\title{
EFFECT OF THE METHOD OF FIBER BUNDLE STRENGTH DETERMINATION ON INFERRING YARN STRENGTH IN EGYPTIAN COTTON
}

\author{
(Received: 15 .10.2012) \\ By \\ O. D. M. Nour and Kh. M.M. Hussein \\ Cotton Research Institute, Agricultural Research Center, Giza, Egypt.
}

\begin{abstract}
This investigation aimed to predict yarn strength for small samples obtained from individual plant yield depending on fiber strength.Seven Egyptian cotton varieties with different grades were used. The HVI, pressley and stelometer at zero and $1 / 8$ gauge were used to determine fiber strength. High positive correlation values among pressley at 0 gauge, pressley at $1 / 8$ gauge, stelometer at $1 / 8$ gauge and HVI instrument in SL and USDA modes were obtained (R ranged from $0.83-1.00$ ). The highest contribution of yarn strength in different counts was HVI-USDA fiber strength $\left(\mathrm{R}^{2}=0.91\right)$, whereas the lowest contribution belongs to pressley fiber strength at $1 / 8$ gauge $\left(\mathrm{R}^{2}=0.78\right)$.

The pressley at 0 gauge and stelometer fiber strength showed good contribution of yarn strength $\left(\mathrm{R}^{2}=\right.$ 0.82 and 0.89 , respectively). So, according to the high correlations among fiber strength measurements and their high contributions of yarn strength, we can use any of these measurements to predict yarn strength especially from pressley and stelometer fiber strength of the small specimens.
\end{abstract}

Key words: correlation, fiber bundle strength, regression, yarn count, yarn strength.

\section{INTRODUCTION}

Fiber bundle strength in view of its importance and impact on the yarn quality expressed by yarn strength is a matter of research by researchers and those who are worthy to be mentioned here, Ahmad et al. (2003), stated that cotton as a natural product is always referred to as a nonhomogeneous raw material due to variations from fiber to fiber, bale to bale, area to area, season to season, growing areas and harvesting methods etc. They also added that fiber bundle strength is the most important cotton fiber character which determines the amount by which fibers can overlap with one another, the greater the overlapping the easier it would be for the fibers to bind together and better yarn strength. Thus fiber bundle strength has a vital influence upon the ultimate yarn strength and fiber bundle strength has a direct influence on yarn strength.

The fiber bundle strength has long been recognized as an importance property of cotton, strength gained such importance that it affects processing performance and product quality, as adopted by Taylor and Godbey, (1993). They also added that cotton producers, merchants and textile mill managers have expressed concern about the reliability of High Volume Instrument (HVI) strength measurements. Additionally, they questioned the accuracy of using these measurements and asked whether it could be used as a selection criterion in developing new varieties for stronger yarns.

In an effort to improve cotton strength measurements, ASTM, (1975) has conducted numerous experiments to investigate factors which contribute to measuring fiber strength. They found that there are major contributions in specimens to improve specimen preparation thus reaching an accurate control of the specimen loading. These efforts produced pressley method and accordingly have been employed to determine the strength of cotton fibers by using a flat bundle of fibers and a simple beam-lever mechanism to break them to improve reproducibility. Also they added that fiber combing and tensioning are devices to provide better fiber alignment.

Taylor and Godbey,(1995), concluded that pressley method needs fiber specimens prepared and pre-tensioned by hand which introduced operator differences. They also added that strength normalization was performed by periodically retesting a reference cotton.

Utilization pressley fiber bundle strength, as indicated by Nomeir et al. (1983), at zero and 1/8 inch gauge clamp spacing to express strength uniformity as the ratio pressley fiber bundle 
strength at 1/8 inch gauge clamp spacing / pressley fiber bundle strength at zero inch gauge clamp spacing.

Ramey and Beaton, (1989), mentioned that the major fiber property contributing to yarn strength is fiber strength, they also added that pressley and stelometer are typical apparatus for bundle strength measurement.

Prediction of yarn properties from fiber specifications and process parameters (for instance yarn count) has been investigated by various researchers, in particular, Ramesh and Rajamanickam, (1995), who concluded that growing naturally, cotton fiber varies in quality. The quality of the yarn is closely related with the quality of the fiber (the most important fiber strength), thus it is difficult to control or to predict the yarn quality according to the fiber quality. Although efforts have been made by Lan, (2002) in this field, and he reached that, due to strength is the force to break a fiber, thicker fiber is stronger for the same variety but there are great variations among the different varieties.

Malik et al. (2011), stated that more robust yarn is one of the most important properties which make it superior in many applications. Furthermore, they also pointed out that tensile strength of a yarn is defined as a maximum load that it will endure without breaking when subjected to uniaxial tensile loading.

Woodhouse, (2000) and Ragini, (2000), stated that yarn count is the expression of the fineness of the yarn.

The purpose of this study was to predict yarn strength for the small samples obtained from individual plant yield depending on fiber bundle strength measured by individual methods.

\section{MATERIAL AND METHODS}

Seven Egyptian cotton varieties were used as a material classified according to local practice in Egypt to extra long staple varieties represented by Giza 70, Giza 87, Giza 88 and Giza 92, and the long staple varieties represented by Giza 80 , Giza 86 and Giza 90.

From each variety, 3 lint grades - according to the Egyptian grading system- extending from Good / Fully Good (G/FG) down to Fully Good Fair / Good (FGF/G) were used. The previously mentioned varieties and their grades were taken from the Egyptian cotton production and marketing season of 2011/2012.

The test methods used for fiber bundle strength were determination of fiber strength by pressley instrument at zero and $1 / 8$ inch gauge clamp spacing using a simple inclined plane breaker and simple specimen preparation and clamp loading techniques. Since the area of the flat bundle could not be readily determined, pressley recommended that a simple ratio of the breaking load and the bundle weight can be used for reporting the results, ASTM: D-1445-1967.

Determination of fiber strength was made by stelometer instrument at $1 / 8$ inch gauge clamp spacing. Known for stelometer is a precision fiber testing instrument for measuring bundle strength and elongation simultaneously using a systematic movement pendulum, therefore the stelometer called a the pendulum instrument and working on the constant rate of loading principle. Normally, the rate of loading used is $1 \mathrm{~kg} / \mathrm{s}$. ASTM: D - 1445 -05-1975.

Determining fiber bundle strength by HVI (High Volume Instrument) using two modes of calibration SL (Span Length cotton calibration samples) or ICC mode (International Cotton Calibration samples), the other mode is USDA (United States Department of Agriculture calibration samples) or HVI (High Volume Instrument calibration samples) according to ASTM: D- 4603-86-1776-1998.

Fibers of the seven Egyptian cotton varieties Giza 70, Giza 80, Giza 86, Giza 87 Giza 88, Giza 90 and Giza 92 were spun to produce carded ring yarns at twist multiplier 3.6 with four counts $(\mathrm{Ne})$ 30, 40, 50, 60 .

Yarn strength expressed in terms of lea count strength product (yarn strength) was measured by using the good-brand lea tester according to ASTM: D-1578- 1967.

The measurements of the materials characterization used in the present study were under controlled atmospheric conditions due to conducted at the laboratories of the Cotton Research Institute, Agricultural Research Center, Giza - Egypt.

Collected data were subjected to the proper of statistical analysis of correlation and regression according to the procedure described by Draper and Smith, (1966) and Little and Hills, (1978) to construct the prediction models .

The regression equation form $Y=\beta_{o}+\beta_{1} X_{1}+$ $\beta_{2} X_{2}$; where $Y$ is the dependent variable "yarn strength", $\beta_{o}$ is the constant, $X_{1}$ and $X_{2}$ are the independent variables "Pressley at 0 gauge fiber bundle strength, Pressley at 1/8 gauge fiber bundle strength, Stelometer fiber bundle strength, HVISL fiber bundle strength and HVI-USDA fiber 
bundle strength". $X_{2}$ is the carded ring yarn count (30-40-50-60) and $\beta_{1}, \beta_{2}$ are the regression coefficients.

The data were statistically analyzed using the computer statistical software package SAS statistical software V.9.1, (2004).

\section{RESULTS AND DISCUSSION}

In order to infer the quality of carded ring yarns (yarn strength) that can be obtained when manufacturing both of small cotton representative specimens and appropriate cotton representative specimens, we will display a description of the results of fiber bundle strength measurements which were determined by a number of instruments on different spaces and modes. Then follows a correlation between these measurements to find out whether one or all the instruments fully reflect the value of fiber bundle strength. Finally, inferring yarn quality represented in yarn strength by creating prediction equation consisting of fiber bundle strength that was determined by the methods included in the study.

\subsection{Description of the fiber bundle strength measurement}

Results in Table (1) show description of the fiber bundle strength measurement which includes; averages of fiber bundle strength determined by the following instruments, pressley at zero and $1 / 8$ inch gauge clamp spacing, stelometer at $1 / 8$ inch gauge clamp spacing and HVI in two modes SL, USDA. These averages involved the three grades $\mathrm{G} / \mathrm{FG}, \mathrm{G}$ and FGF/G specific for each variety Giza70, Giza 80, Giza 86, Giza 87, Giza 88, Giza 90, and Giza 92. As well as, minimum, mean and maximum of each fiber bundle strength determined by a specific instrument in addition to a certain space (zero and $1 / 8$ inch gauge clamp spacing) and modes of calibration (SL and USDA) regardless of varieties and grades.

With regard to pressley strength measurements we find that fiber bundle strength at zero inch gauge was higher in general than fiber bundle strength determined by pressley at $1 / 8$ inch gauge in all varieties and grades. For example, minimum, mean and maximum for fiber bundle strength at zero and 1/8 inch gauge regardless of varieties and grades were respectively $7.65,3.48$, 9.96, 5.23, 11.74 and 6.69.

This is accepted due to Smith, (1997), who reported that pressley instrument when measuring cotton fiber bundles at $1 / 8$ inch $(3.2 \mathrm{~mm})$ gauge clamp spacing, the bundles lost about half of their strength when broken at a $3.2 \mathrm{~mm}$ gauge length instead of a zero gauge clamp spacing. This decrease in values of pressley fiber bundle strength at $1 / 8$ inch $(3.2 \mathrm{~mm})$ gauge clamp spacing is interpreted by Nomeir et al. (1983). At $1 / 8$ inch $(3.2 \mathrm{~mm})$ gauge clamp spacing the pressley cutter weight affects first the weakest point in the bundle leading to low strength values.

The Stelometer fiber strength at $1 / 8$ inch $(3.2$ $\mathrm{mm})$ gauge $(30.78 \mathrm{~g} / \mathrm{tex})$ was close, to some degree with fiber bundle strength that determined by HVI-SL (31.97 g/tex). On the other hand, HVIUSDA fiber bundle strength showed the highest fiber bundle strength values $(42.84 \mathrm{~g} / \mathrm{tex})$.

ASTM, (1986, 1993a and 1998) produced that the tensile (fiber bundle strength) testing instruments- in general- operate according to Constant Rate of Loading (C.R.L) methodology "an apparatus in which the rate of crease of the force is uniform with time after 3-sec. and the specimen is free to elongate, this elongation being dependent on the extension characteristics of the specimen".

Fiber bundle strength of HVI-USDA is higher than HVI-SL fiber strength as clarified Table (1), that's due to variation of standard readings of both SL and USDA calibration samples. The HVI instrument operates according to Constant Rate of Loading (C.R.L) regardless the calibration modes whether SL or USDA..

\subsection{Correlation between individual and HVI instruments in different modes used for determining fiber bundle strength}

The intercorrelations among individual methods and HVI in the two modes are shown in Table (2).

The correlation matrix reflecting the highly significance correlation between each of individual and HVI instruments regardless the space measuring fiber bundle strength if was either zero or $1 / 8$ inch gauge clamp spacing, and also modes of calibration specific HVI whether was SL or USDA.

By reviewing Table (2), will find the following; pressley instrument when measuring fiber bundle strength at a certain space zero inch gauge clamp spacing correlated positively in high significance with pressley fiber bundle strength at a certain space $1 / 8$ inch gauge clamp spacing as well as stelometer fiber bundle strength at a certain space $1 / 8$ inch gauge clamp spacing and HVI fiber bundle strength at the same space (1/8 inch gauge clamp spacing) in the two modes of calibration SL and USDA standards calibration samples, the correlation values were, $0.85^{* *}$, $0.90^{* * *}, 0.90^{* * *}, 0.87^{* * *}$ respectively. Similarly, also 
Table (1). Description of fiber bundle strength measurements related to 3 grades of 7 Egyptian cotton varieties determined by individual and HVI instruments as well as different modes.

\begin{tabular}{|c|c|c|c|c|c|c|}
\hline \multirow[b]{2}{*}{ Varieties } & \multirow[b]{2}{*}{ Grades } & \multicolumn{5}{|c|}{ Instruments } \\
\hline & & $\begin{array}{c}\text { Pressley at } \\
\text { o gauge }\end{array}$ & $\begin{array}{c}\text { Pressley at } \\
18 \text { gauge }\end{array}$ & Stelometer & HV-SL & $\begin{array}{l}\text { HVI- } \\
\text { USDA }\end{array}$ \\
\hline \multirow{3}{*}{ Giza 70} & G/FG & 10.93 & 5.55 & 33.48 & 34.62 & 44.62 \\
\hline & $\mathbf{G}$ & 10.13 & 4.91 & 31.91 & 33.05 & 43.05 \\
\hline & FGF/G & 9.53 & 4.66 & 31.51 & 32.65 & 42.65 \\
\hline \multirow{3}{*}{ Giza 80} & G/FG & 9.77 & 4.94 & 28.58 & 29.72 & 38.09 \\
\hline & G & 9.07 & 4.23 & 27.50 & 28.64 & 37.01 \\
\hline & FGF/G & 7.91 & 3.68 & 25.40 & 26.54 & 34.91 \\
\hline \multirow{3}{*}{ Giza 86} & G/FG & 10.50 & 5.50 & 31.45 & 32.69 & 41.96 \\
\hline & G & 9.80 & 4.78 & 30.43 & 31.67 & 40.78 \\
\hline & FGF/G & 9.07 & 4.50 & 28.04 & 29.28 & 39.99 \\
\hline \multirow{3}{*}{ Giza 87} & G/FG & 11.07 & 6.39 & 35.12 & 36.57 & 50.23 \\
\hline & G & 10.67 & 6.20 & 34.18 & 35.63 & 48.41 \\
\hline & FGF/G & 10.13 & 5.59 & 33.85 & 35.30 & 47.29 \\
\hline \multirow{3}{*}{ Giza 88} & G/FG & 11.33 & 6.55 & 34.03 & 35.17 & 48.32 \\
\hline & G & 10.47 & 6.00 & 32.96 & 34.10 & 47.25 \\
\hline & FGF/G & 10.10 & 5.63 & 32.44 & 33.58 & 46.73 \\
\hline \multirow{3}{*}{ Giza 90} & G/FG & 9.70 & 4.78 & 25.74 & 26.88 & 36.39 \\
\hline & G & 8.30 & 4.04 & 23.83 & 24.97 & 34.48 \\
\hline & FGF/G & 7.65 & 3.48 & 22.44 & 23.58 & 33.09 \\
\hline \multirow{3}{*}{ Giza 92} & G/FG & 11.74 & 6.50 & 35.43 & 36.49 & 49.04 \\
\hline & G & 10.85 & 6.69 & 34.37 & 35.43 & 47.98 \\
\hline & FGF/G & 10.37 & 5.24 & 33.72 & 34.78 & 47.33 \\
\hline \multicolumn{2}{|c|}{ Minimum } & 7.65 & 3.48 & 22.44 & 23.58 & 33.09 \\
\hline \multicolumn{2}{|c|}{ Mean } & 9.96 & 5.23 & 30.78 & 31.97 & 42.84 \\
\hline \multicolumn{2}{|c|}{ Maximum } & 11.74 & 6.69 & 35.43 & 36.57 & 50.23 \\
\hline
\end{tabular}

G/FG = Good to Fully Good, G = Good, FGF/G = Fully Good Fair to Good.

HVI = High Volume Instrument. SL = Span Length mode of calibration. USDA = United States Department of Agriculture mode of calibration.

Table (2): Correlation matrix which reflect values of the correlation between individual and HVI instrument in different modes been used for determining fiber bundle strength

\begin{tabular}{|c|c|c|c|c|}
\hline & $\begin{array}{c}\text { Pressley } \\
\text { at } \text { gauge }\end{array}$ & $\begin{array}{c}\text { Pressley at } \\
\text { 18 gauge }\end{array}$ & $\begin{array}{c}\text { Stelo } \\
\text { meter }\end{array}$ & $\begin{array}{c}\text { HVI } \\
\text {-SL }\end{array}$ \\
\hline $\begin{array}{c}\text { Pressley at } \\
\text { gauge }\end{array}$ & $\mathbf{0 . 8 5}^{* *}$ & & & \\
\hline Stelometer & $\mathbf{0 . 9 0}^{* *}$ & $\mathbf{0 . 8 3}^{* *}$ & & \\
\hline HVI-SL & $\mathbf{0 . 9 0}^{* *}$ & $\mathbf{0 . 8 3}^{* *}$ & 1.00 & \\
\hline HVI-USDA & $\mathbf{0 . 8 7}^{* *}$ & $\mathbf{0 . 8 5}$ & $\mathbf{0 . 9 7}^{* *}$ & $\mathbf{0 . 9 7}^{* *}$ \\
\hline
\end{tabular}

stelometer when measuring fiber bundle strength at a certain space $1 / 8$ inch gauge clamp spacing correlated positively in high significance arrived at 1.0 with HVI- SL fiber bundle strength and $0.97^{* * *}$ with HVI- USDA fiber bundle strength.

The interpretation of the previous results which showed the correlation values in highly positive significance between the fiber bundle strength of each determination on different instrument and modes will be through the review method of how each instrument whether was individual (pressley - stelometer) or HVI measuring fiber bundle strength as well as the general definition of strength.

Smith, (1997), as we mentioned previously, reached that pressley instrument when measures cotton fiber bundles at zero and $1 / 8$ inch $(3.2 \mathrm{~mm})$ gauge clamp spacing, the bundles lost about half of their strength when broken at a $3.2 \mathrm{~mm}$ gauge length instead of a zero gauge, in spite of this, values of fiber bundle strength correlated in highly positive significance, which means that any of these gauge clamp spacing (zero $-1 / 8$ inch) fully reflect actual fiber bundle strength.

In case of stelometer fiber bundle strength, Taylor and Godbey, (1995), reported that it is measured by $1 / 8$ inch $(3.2 \mathrm{~mm})$ gauge clamp spacing and the bundle mass (in kilograms) motion control takes the pendulum form.

ASTM (1993a, 1993b) stated that HVI motion control which measures fiber bundle strength is 
unique in several factors among them speed (less than 10 seconds) and jaw face in leather.

These two former factors lead to utilizing the length gauge to sense the beard mass and signal the strength tester when the proper mass was reached, enabling the specimens to be broken at a constant mass, thus eliminating the necessity for weighing.

The general definition of fiber bundle strength as a certain weight of a bundle of fibers in face of the cutting force, this so-called pressley index (the cutter force in pounds/fiber bundle weight in milligrams) of zero and $1 / 8$ inch gauge clamp spacing, as in the case of stelometer and HVI, fiber bundle strength results will be in expression of tex (grams-force per tex) (gf/tex).

\subsection{Inferring carded ring yarn strength (yarn strength)}

This part concerns the statistical regression according to Draper and Smith, (1966).

Results in Table (3) clarify the statistical parameters of which most important is the regression coefficient ; $\beta_{\mathrm{o}}$ is the constant regression coefficient, $\beta_{1}$ is the regression coefficient specific each fiber bundle strength which determined by individual and HVI instruments, $\beta_{2}$ is the regression coefficient specific carded ring yarn counts. Predictors as present in Table (3), pressley at 0 gauge fiber bundle strength, pressley at $1 / 8$ gauge fiber bundle strength, stelometer fiber bundle strength, HVI-SL fiber bundle strength, HVI-USDA fiber bundle strength and carded ring yarn count (count). Table (3) also clarifies the linear regression models and its coefficients of determination $\left(R^{2}\right)$, which reflect the degree of accuracy of each linear regression model.

With regard to regression coefficients present in Table (3), the slope values ( $\beta$ ) of individual and HVI instruments that used for determining fiber bundle strength were respectively pressley at 0 gauge fiber bundle strength $\left(\beta_{1}=408.26\right)$, pressley at $1 / 8$ gauge fiber bundle strength $\left(\beta_{1}=424.22\right)$, stelometer fiber bundle strength $\left(\beta_{1}=119.69\right)$, HVI-SL fiber bundle strength $\left(\beta_{1}=118.84\right)$ and HVI-USDA fiber bundle strength $\left(\beta_{1}=87.03\right)$. These values tell the line slopes upward and consequently there is an increasing relationship between yarn strength and fiber bundle strength regardless of the instrument whether individual or HVI in different modes has determined it. On the other hand, Table (3) shows that the regression coefficient for yarn count was negative constant contributor $\left(\beta_{2}=-10.43\right)$, and that tells yarn count slopes downward in all linear regression models contained in Table (3).

These previous results are accepted due to coefficient of determination $\left(\mathrm{R}^{2}\right)$ specific to each linear regression model in Table (3) was in highly

Table (3). Predictors, statistical parameters and linear regression models used to infer yarn strength

\begin{tabular}{|c|c|c|c|c|}
\hline \multirow[t]{2}{*}{ Predictors } & \multicolumn{4}{|c|}{ Statistical Parameters } \\
\hline & $\begin{array}{l}\text { Regression } \\
\text { Coefficients }\end{array}$ & $\begin{array}{c}\text { Standard } \\
\text { Error }\end{array}$ & T. Stat. & P - value \\
\hline Constant & $\beta_{0}=-757.82$ & 135.6 & -5.59 & 0.000 \\
\hline Pressley at 0 gauge & $\beta_{1}=408.26$ & 12.41 & 32.89 & 0.000 \\
\hline Count & $\beta_{2}=-10.43$ & 1.199 & -8.70 & $\mathbf{0 . 0 0 0}$ \\
\hline \multicolumn{5}{|c|}{ Yarn Strength $=-757.82+408.26 *($ Pressley at 0 gauge $)-10.43 *($ Count $), \mathbf{R 2}=0.82$} \\
\hline Constant & $\beta_{0}=1087.66$ & 99.96 & 10.88 & 0.000 \\
\hline Pressley at $1 / 8$ gauge & $\beta_{1}=424.22$ & 14.91 & 28.45 & 0.000 \\
\hline Count & $\beta_{2}=-10.438$ & 1.344 & -7.76 & 0.000 \\
\hline \multicolumn{5}{|c|}{ Yarn Strength $=1087.66+424.22 *($ Pressley at 18 gauge $)-10.43 *($ Count $), R^{2}=0.78$} \\
\hline Constant & $\beta_{0}=-375.46$ & 94.97 & -3.95 & $\mathbf{0 . 0 0 0}$ \\
\hline Stelometer & $\beta_{1}=119.69$ & 2.739 & 43.71 & 0.000 \\
\hline Count & $\beta_{2}=-10.43$ & 0.9414 & -11.09 & 0.000 \\
\hline \multicolumn{5}{|c|}{ Yarn Strength $=-375.46+119.69 *($ Stelometer $)-10.43 *($ Count $), \mathbf{R}^{2}=\mathbf{0 . 8 9}$} \\
\hline Constant & $\beta_{0}=-490.59$ & 96.98 & -5.06 & 0.000 \\
\hline HVI-SL & $\beta_{1}=118.84$ & 2.709 & 43.86 & 0.000 \\
\hline Count & $\beta_{2}=-10.43$ & 0.9383 & -11.12 & 0.000 \\
\hline \multicolumn{5}{|c|}{ Yarn Strength $=-490.59+118.84 *($ HVI - SL $)-10.43 *($ Count $), \mathbf{R}^{2}=\mathbf{0 . 8 9}$} \\
\hline Constant & $\beta_{0}=-419.01$ & 85.29 & -4.91 & 0.000 \\
\hline HVI-USDA & $\beta_{1}=87.03$ & 1.767 & 49.25 & 0.000 \\
\hline Count & $\beta_{2}=-10.43$ & 0.8458 & -12.34 & 0.000 \\
\hline
\end{tabular}


positive values, since the coefficient of determination $\left(\mathrm{R}^{2}\right)$ is an indicator of the percentage of variation. Pressley at 0 gauge fiber bundle strength explains the variation in yarn strength by approximately 0.82 , also the percentage of variation $\left(R^{2}\right)$ reflects a strong relation between pressley at 0 gauge fiber bundle strength and yarn strength.

The former interpretation applies to the relationship between yarn strength and both of pressley at $1 / 8$ gauge fiber bundle strength, stelometer fiber bundle strength, HVI-SL fiber bundle strength and HVI-USDA fiber bundle strength with values of $\mathrm{R}^{2},(0.78,0.89,0.89,0.91)$, respectively.

From Table (3) we come to the following; conclusions regardless the instruments or modes useed in the determination of fiber bundle strength, the larger the share of fiber bundle strength the higher is the yarn strength. Similarly, Ahmad et al. (2003) stated that fiber bundle strength has a direct influence on yarn strength.

According to Woodhouse, (2000) and Ragini, (2000), in the definition of yarn count; decreasing yarn count as yarn gets coarser, leading to the higher the share of yarn count the lower is the carded ring yarn strength. Ramey and Beaton, (1989) and Malik et al. (2011), reached the same conclusion.

As a result of highly significant and positive values of the correlation of Pressley and Stelometer fiber strength measurements with HVI fiber strength in the two modes (SL and USDA), and also the high contributions of these measurements to yarn strength. So it could be determine fiber strength of small representative specimens using individual methods (Pressley and Stelometer) within degree of accuracy similar to the degree of HVI accuracy, as well as, we can infer the quality of the manufacture of which is represented in the carded ring yarn strength (yarn strength) using the regression models as follows:

Yarn Strength $=-757.82+408.26$ (Pressley at 0 gauge) $-10.43 *$ (Count), $\mathrm{R}^{2}=0.82$.

Yarn Strength $=1087.66+424.22 *$ (Pressley at $1 / 8$ gauge) $-10.43 *$ (Count), $\mathrm{R}^{2}=0.78$.

Yarn Strength $=-375.46+119.69 *$

(Stelometer) $-10.43 *$ (Count), $\mathrm{R}^{2}=0.89$.

Measuring fiber bundle strength by using HVI instrument in two modes of calibration (SL and USDA) standard calibration sample in the same degree of precision as indicated by the values of the correlation of high positive, as well as, inferring the carded ring yarn strength (yarn strength) from slopes at each of fiber bundle strength and carded ring yarns count (count) by using regression models specific HVI in each mode as follows

Yarn Strength $=-490.59+118.84 *(\mathrm{HVI}-\mathrm{SL})-$ $10.43 *$ (Count), $\mathrm{R}^{2}=0.89$.

Yarn Strength $=-419.01+87.03 *($ HVI USDA) $-10.43 *$ (Count), $\mathrm{R}^{2}=0.91$.

In conclusion, the results indicated that highly significant correlations were found between each of individual and HVI instruments regardless the space measuring fiber bundle strength specific pressley and stelometer if was zero either or $1 / 8$ inch gauge clamp spacing, nor modes of calibration specific HVI whether was SL or USDA, means that any of these methods fully reflect actual fiber bundle strength.

Inferring the quality of carded ring yarns (yarn strength) that can be obtained when manufacturing small cotton representative specimens by using the regression models for pressley when measuring fiber bundle strength at a certain space zero, 1/8 inch gauge clamp spacing and stelometer as follows:

Yarn Strength $=-757.82+408.26$ (Pressley at 0 gauge) $-10.43 *$ (Count), $\mathrm{R}^{2}=0.82$.

Yarn Strength $=1087.66+424.22 *($ Pressley at $1 / 8$ gauge) $-10.43 *$ (Count), $\mathrm{R}^{2}=0.78$.

Yarn Strength $=-375.46+119.69 *$ (Stelometer) - $10.43 *$ (Count), $\mathrm{R}^{2}=0.89$.

Inferring the quality of carded ring yarns (yarn strength) that can be obtained when manufacturing appropriate cotton representative specimens by using the regression models for HVI instrument when measuring fiber bundle strength in two modes of calibration (SL - USDA) as follows

Yarn Strength $=-490.59+118.84 *(\mathrm{HVI}-\mathrm{SL})-$ $10.43 *$ (Count), $\mathrm{R}^{2}=0.89$.

Yarn Strength $=-419.01+87.03 *(\mathrm{HVI}-$ USDA) $-10.43 *$ (Count), $\mathrm{R}^{2}=0.91$.

\section{REFERENCES}

Ahmad I., Nawaz .SH. M. and Tayyab. M. (2003). Influence of cotton fiber fineness and staple length upon yarn lea strength. International Journal of Agriculture \& Biology.05 (4) pp. 642-644.

ASTM . American Society for Testing Materials .. (1952). Annual book of standards, D-41452T. Philadelphia, pp. 307-327.

ASTM. American Society for Testing Materials . (1967). Standard test method. D-1445-67, D1578-67. 
ASTM. American Society for Testing and Materials. (1975). Committee D-13, Textiles, Designation: D 1445-05- 1975, breaking strength and elongation of cotton fibers.

ASTM. American Society for Testing Materials. (1986). Standard test method of cotton fibers by High Volume Instrument (HVI), D-460386. Philadelphia, U.S.A.

ASTM. American Society for Testing Materials (1993a). Standard test method designation D 1445-90 for breaking strength and elongation of cotton fibers (flat bundle method). Annual Book of ASTM Standards, Vol. 07. 01.

ASTM. American Society for Testing Materials. (1993b). Standard test method designation D 4605-86. for measurement of cotton fibers by high volume instruments (HVI) (Spinlab System of Zellweger Uster,Inc.) Annual Book of ASTM Standards, Vol. 07.02.

ASTM. American Society for Testing Materials (1998). Standard test method of cotton fibers by High Volume Instrument (HVI), D-177698. Philadelphia 3, Pa, U.S.A.

Draper N. R. and Smith H. (1966). Applied regression analysis. John Wiley and Sons, New York.

Lan S.H. (2002). Study on the quality control of semi-manufactured products. Proceedings of 2002 Conference of Jiangsu Textile Society, P. 11.

Little T.M. and Hills.E.J. (1978). Agricultural experimentation design and analysis. John Wiley and Sons. New York - ChichesterBrisbane-Toronto. 350pp.

Malik Z.A., Malik M. H., Hussain T. and Arain F. A. (2011). Development of models to predict tensile strength of cotton woven fabrics. Journal of Engineered Fibers and Fabrics .6 (4). pp.46-53.

Nomeir A.A., Nafisa T. and Kamal M.M. (1983). Effect of mercerization on fiber structural and mechanical properties of some American and Egyptian cotton varieties. Agric. Res. Rev.9:207 - 218.

Ragini International. (2000). Available from www.raginiyarns.com.

Ramesh M. C. and Rajamanickam R. (1995). The prediction of yarn tensile properties by using artificial neural networks, J. Textile Inst. Vol. 86, 1995, pp. 459 - 469.

Ramey H.H. and Beaton P.G. (1989). Relationship between short fiber content and HVI fiber length uniformity. Text. Res. J., 59: 101-8.

SAS. (2004). SAS version 9.1. User's guide. Cary, NC: SAS institute, Inc.

Smith H. R. (1997). Significant events leading to the development of high speed measurements of cotton fiber strength. International Textile Center (ITC) Fiber Property seminar, available from www.ttu.edu/-itc.

Taylor R. A. and Godbey L. C.(1993). A reference method for HVI strength. Beltwide cotton conferences, national cotton council, Memphis, Tennessee, pp. 1076-1079.

Taylor R. A. and Godbey L. C. (1995). Why we need a standard strength test for cotton variety selection. Beltwide cotton conferences, pp. 1175-1178.

Woodhouse T. (2000). Yarn counts and calculations. Oxford technical manuals. Edinburgh, pp.5 -7. 
تأثير طريقة تقدير متانة الخصلة على إستتناج متانة خيوط الغزل فى القطن المصرى أسامة دسوقى محمد نور - خالا محمد محمد حسين

$$
\text { مركز البحوث الزر اعية- معهد بحوث القطن - الجيزة- مصر }
$$

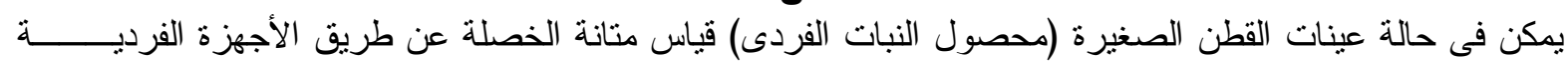

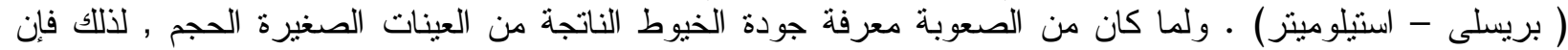

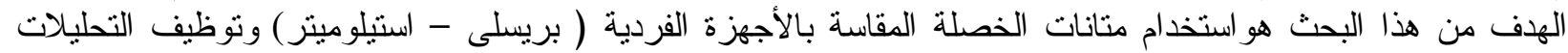

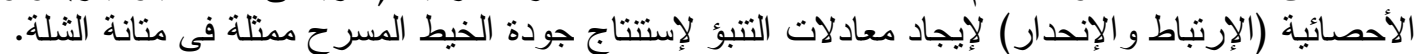

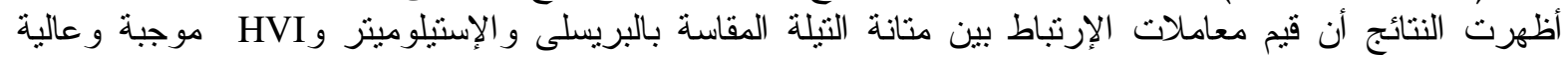

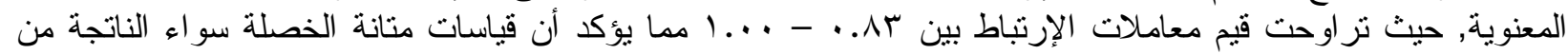

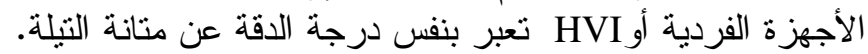
كانت معادلات الإنحدار التى عن طريقها تم إستتناج متانة الثنلة, تتسم بدرجة عالية مانة من الدقة وفقا لقيمة معامل

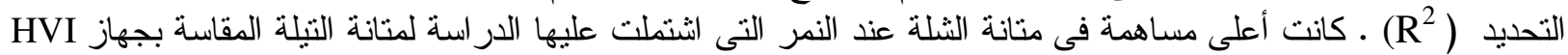

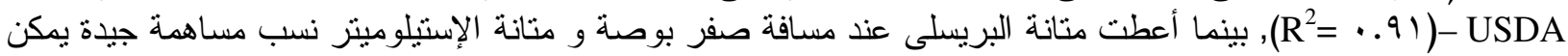
الإعتماد عليها فى إستنتاج متانة الثلة من معادلتى الإنحدار الآتيتين: Yarn Strength $=-757.82+408.26$ (Pressley at 0 gauge) $-10.43 *$ (Count), $\mathrm{R}^{2}=0.82$ Yarn Strength $=-375.46+119.69 *($ Stelometer $)-10.43 *($ Count $), \mathrm{R}^{2}=0.89$

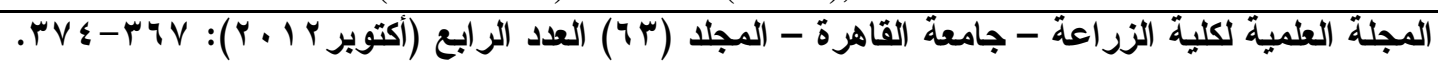

